\title{
LIMITAÇÕES JURÍDICAS À EXPERIMENTAÇÃO NO NOVO ESTATUTO DOS ANIMAIS
}

\section{LEGAL LIMITATIONS REGARDING EXPERIMENTATION IN THE NEW ANIMALS ACT}

\author{
${ }^{1}$ Vera Lucia da Silva \\ ${ }^{2}$ Marcelo Saccardo Branco
}

\section{RESUMO}

Este artigo apresenta os dispositivos sobre experimentação previstos no Estatuto dos Animais. Inicialmente, foi realizada uma abordagem teórica do biodireito e da bioética. A seguir, é mencionada a Lei Arouca, norma vigente que regulamenta o artigo 225 da Constituição Federal e autoriza a experimentação em animais. Posteriormente, são destacados elementos dos Projetos de Lei que visam alterar a Lei Arouca, em tramitação no Senado Federal. O objetivo é apresentar uma interpretação do caráter protetivo mais abrangente do Estatuto dos Animais quanto ao uso destes em experimentos científicos.

Palavras-chave: Bioética, Biodireito, Experimentação animal, Lei arouca, Estatuto dos animais

\begin{abstract}
This article introduces the Animal Act provisions about animal testing. At first, it was proposed a bioethical and biolaw theoretical approach. Following, it was mentioned the Arouca Law, current norm that rules the Article 225 on the Federal Constitution, and authorizes experiments on animals. Then was introduced some elements of the Bills in proceeding at the Senate aimed at changing the Arouca Law. The point is to present an interpretation that focus on a wider view of the Animal Act protective aspect, especially concerning animal testing.
\end{abstract}

Keywords: Bioethics, Biolaw, Animal experiments, Arouca law, Animal protection act

\footnotetext{
${ }^{1}$ Doutora em Direito pela Universidade Federal de Santa Catarina - UFSC, Florianópolis - SC (Brasil).

E-mail: veralms@ hotmail.com

${ }^{2}$ Graduado em Direito pela Universidade do Vale do Itajaí - UNIVALI, Itajaí - SC (Brasil).

E-mail: msbadvogado@hotmail.com
} 


\section{INTRODUÇÃO}

A regulamentação jurídica da experimentação animal no Brasil demanda tratamento mais adequado às discussões éticas sobre o uso de seres vivos em pesquisas científicas. A previsão constitucional do dever de proteção aos animais por parte de toda a sociedade, insculpida no seu artigo 225, ganhou maior concretude com a promulgação da Lei n. 11.794, de 08 de outubro de 2008, conhecida popularmente como Lei Arouca. Entretanto, referida norma revelou-se insuficiente em tal mister, diante das reivindicações de atores sociais, tais como organizações não-governamentais, cidadãos e, até mesmo, setores de pesquisa científica, em prol de um novo regramento para o uso de animais em experimentos.

Para abordar a exigência social pela mudança do regramento jurídico concernente à experimentação animal, é necessário perceber a fundamentação teórica base das reivindicações. Portanto, situar os conceitos essenciais ao Biodireito e à Bioética é o primeiro esforço de um trabalho sobre a matéria. Mais que uma investigação conceitual, é preciso vislumbrar a mudança de paradigma sobre a consideração da vida sob a qual ganha sentido demandar respeito aos direitos dos animais. Essa é a pretensão da primeira parte dessa pesquisa.

Dada a perspectiva de unidade entre ciência e ética, base epistemológica do Biodireito, é possível avaliar a discrepância entre a legislação vigente no país e as exigências correspondentes a um modelo efetivamente ético de regramento das experiências científicas. Todos os procedimentos que impliquem sofrimento de um ser vivo são questionáveis, ainda que a justificativa para tal possa ser compreendida sob um sistema utilitarista de legitimação científica. A questão é que, sob um horizonte em que ciência e ética são igualmente necessárias à formação do conhecimento, não há sentido em legitimar qualquer forma de imposição de sofrimento aos seres vivos.

Nesse sentido, a legislação vigente é permissiva e bastante comprometida com os objetivos das indústrias de experimentação animal. Mesmo com a criação de Conselhos regulamentares e de fiscalização das pesquisas com uso de animais, a proteção à vida ainda não surge como elemento normativo fundamental. Ademais, a diminuta participação social nesses Conselhos e o predomínio dos técnicos revelam a atenção dispensada à discursividade supostamente científica em detrimento da dimensão social da questão. Tal ponto de reflexão passa a ser elucidado na segunda parte desta pesquisa. 
Diante da dissonância entre a discussão ética do (possível?) uso da vida e a legislação atual, novas propostas de Lei tem sido apresentadas pelas casas legislativas brasileiras. Ainda que os interesses em jogo sejam diversos e, muitas das vezes, justificados por razões eminentemente comerciais, o debate sobre a matéria tem sido considerado necessário. A cobrança da sociedade impõe urgência na promulgação de normas infraconstitucionais que visem regular a proteção jurídica aos animais, por força do artigo 225 da Constituição Federal . O escrutínio da motivação de agentes sociais em prol de maior tutela aos direitos dos animais, bem como os Projetos de Lei atualmente em trâmite nas casas legislativas brasileiras passa a ser o objeto da terceira seção apresentada neste trabalho.

A tramitação de um projeto de lei específico que prevê o Estatuto dos Animais iniciou-se também no Senado Federal, em 2015 (PLS 631/2015). Este é um projeto de pretensões mais amplas, com a inserção dos animais na esfera jurídica para além do direito das coisas. O tema experimentação animal retorna, ainda que transversalmente, nessa nova proposta legislativa. O projeto do Estatuto dos Animais e suas emendas serão analisadas na quarta seção, onde também será proposta uma hermenêutica deste diploma legal que conduz à vedação do uso de animais em pesquisas científicas.

Finalmente, o objetivo dos autores é apresentar e compreender as mudanças propostas à legislação brasileira atual, verificando os limites tanto do paradigma vigente como dos projetos de lei que o altera. Apresenta-se, como possibilidade de efetiva transformação da perspectiva do uso de animais em experimentos, a aceitação de um paradigma bioético para as pesquisas e a responsabilização humana sobre a vida.

\section{BIODIREITO COMO LIMITE À EXPERIMENTAÇÃO ANIMAL}

O biodireito é um neologismo que vem revolucionar a ciência. O que ele busca, fundamentalmente, como a Bioética, é trazer para a seara científica o debate ético. A ciência afastou-se da ética, comprometeu-se a economia e continuou de mãos dadas com a política. Tal distanciamento entre ciência e ética limitou as discussões de interesse de todos à técnica, afastando a sociedade dos debates importantes para a própria vida.

Nessa perspectiva, o biodireito, como saber transdisciplinar, vem a recolocar em foco a discussão sobre a vida e de sua relação com o universo normativo-jurídico. Apropriar-se da ideia de poli-super-meta-máquina, definida por Edgar Morin, é um aceno à consideração dos 
seres vivos para além de fragmentos biológicos, como unidade complexa e indissociável produtores de si em seu meio. O papel do biodireito, portanto, é reavivar uma dimensão não determinista dos seres vivos, enquanto relações complexas.

\begin{abstract}
O enraizamento físico de tudo o que é vida não está apenas no caráter químico de todas as operações de um organismo, nem, é claro, somente na obediência às Leis da Natureza, como a da queda dos corpos. Ele é, sobretudo, de natureza organizacionista: o pertencimento à Família Máquina. Os seres vivos podem ser definidos como seres físicos produtores-de-si, dotados de qualidades originais ditas biológicas, o termo biologia remetendo às complexidades específicas de sua organização e às emergências globais indissociáveis desses seres enquanto todo. (MORIN, 2005, p.339)
\end{abstract}

Essa consideração da vida como complexidade permite destacar, a priori, que a crise que afeta a humanidade é única, que é de percepção - essencialmente da vida. A grande crise se deve à fragmentação do saber, à cultura disciplinar a todos imposta. A separação dos saberes, especialmente sedimentada na dita cultura da modernidade, contribui para a proliferação do individualismo, para a separação da individualidade da coletividade, para a construção de um conceito liberal e ideal de cidadania. Nessa perspectiva, a preocupação com os diversos usos que o conhecimento científico está fazendo com a vida permanece negligenciada, obscurecida pela noção exacerbadamente individualista.

Vale dizer que essa crise de percepção determinada pelo individualismo, faz do sujeito um ser livre na sua escravidão, porquanto vive a democracia em uma ditadura, em que pode escolher livremente votar e ser votado. Enfim, por ter o direito a ser feliz em uma sociedade de consumo. O conceito de responsabilidade enquanto ser vivo por si e pelo bios, como unidade, sucumbe ao poder econômico, centralizado na ideia fragmentária de vida, indiferente à integridade (MORIN, 2001, p.76).

No processo eleitoral o que mais se propõe é resolver o problema da saúde, como se as medidas governamentais fossem suficientes para solucioná-la. É como se a saúde pudesse ser dada, proporcionada, mesmo para aqueles que não a querem. Temos que superar a cultura patriarcal da irresponsabilidade, em que o sujeito é guiado pelo direito, tutelado pelo médico e disciplinado pelo educador.

Por essa via de pensamento fragmentário, que divorcia ética e ciência, é que se legitimam decisões públicas. Estas seguem inquestionáveis, travestidas de ciência, comprometidas com o poder econômico e não com a vida. O tecnicismo científico irresponsável retira da sociedade discussões fundamentais sobre a vida, colocando-as em 
segundo plano. Em troca, tem-se o cômodo modus vivendi, conduzido pelo marketing hipnótico e vazio de sentido (FAGUNDEZ, 2003, p.74).

Importante mesmo é a superação dessa epistemologia da cegueira, expressão empregada por Boaventura de Sousa Santos, para que possa emergir uma epistemologia que objetive a emancipação (SANTOS, 2009, p.134). Para que isso ocorra, é preciso derrubar as fronteiras da ciência, em direção a um conhecimento pelo menos interdisciplinar. Assim, é necessário, com urgência, despertar para um Direito Educacional, para uma Medicina Educacional, que respeite a diversidade das culturas e as diferentes formas de vida.

Diz Morin, com acerto, que os indivíduos produzem a sociedade e a sociedade produz os indivíduos (MORIN, 2001, p. 39). Ou seja, a cultura patriarcal nasce a partir de cada sujeito, competindo a ele reproduzir. A microfísica do poder se expressa na determinação do tratamento por parte do médico, sem que haja qualquer tipo de questionamento. Não há saúde pública sem saúde individual. Não há saúde individual sem um projeto pedagógico de saúde pública.

Sob a justificativa pública da saúde (e de sua aparência), é produzida e comercializada diariamente uma vasta gama de drogas. Além dos fármacos, as aparentes saúde e jovialidade, no universo do consumo, podem ser adquiridas por meio dos cosméticos. O medo da dor, propagado pelo marketing, faz necessária a criação de soluções milagrosas, que não questionam o próprio modus vivendi comodista. Ainda que seus efeitos sejam incertos, a promessa de boa vida transmitida pelas descobertas milagrosas da ciência é vendida a altos custos, não apenas financeiros, como também de vidas.

Além de segregar os que podem pagar por esses custos financeiros, separando os que podem e os que não podem acessar a vida saudável, a indústria da saúde ainda segrega a vida entre digna e insignificante. Nesse último grupo, ingressam os animais, considerados como objetos de ciência e de pesquisa, sujeitos a toda espécie de uso legalmente autorizado. Segundo Sônia T. Felipe:

\footnotetext{
Meio bilhão de animais são torturados, literalmente, nos laboratórios ao redor do planeta, a cada ano, para satisfazer a uma demanda criada, por sua vez, por outros laboratórios, os de propaganda. Estes não revelam um dos componentes mais frequentemente usados nas formulas miraculosas prometidas nos comerciais: a dor e o tormento pelo qual passaram aqueles milhões de animais nos testes do produto. Os consumidores, atentos aos seus 'direitos humanos' relacionados ao conforto e ao bem-estar, facilmente ignoram os 'direitos dos animais' de não serem usados para tais fins, quando sua natureza viva dispensa todos esses cosméticos, produtos de higiene e limpeza e a maioria absoluta das drogas para as quais são usados como 'cobaias'. (FELIPE, 2014, p.290)
} 
A AMA (American Medical Association) tem sistematicamente de informar os médicos acerca dos efeitos adversos dos antibióticos, que são os medicamentos de que os médicos mais abusam e os mais perigosos para os pacientes. A prescrição desnecessária ou negligente dos antibióticos resultou em milhares de mortes de todas as formas de vida, especialmente dos animais usados como cobaias. No entanto, a AMA concede espaço publicitário ilimitado dos antibióticos, sem a mínima rejeição ou ressalva de conteúdo dos anúncios. A publicidade está relacionada com o fato de que, depois dos sedativos, são os medicamentos mais vendidos.

Esse fato corriqueiro inclui não apenas o sofrimento humano, com o uso indiscriminado e irresponsável de drogas, mas também uma dor que não é mensurada: a dos animais envolvidos nas pesquisas científicas. O respaldo social ao uso dessas substâncias é conquistado pela publicidade, financiado pelos lobbies que envolvem as diversas indústrias que lucram com essas atividades. Entre estas, devem ser incluídas não apenas as empresas de fármacos, mas também e essencialmente esquecidas, os laboratórios de experimentação animal.

A influência das indústrias da dor transcende o que chega ao consumidor final das drogas. Tem massiva interface com o poder e com a política, financiando sistemas de decisão e norteando a formação de normas, supostamente técnicas. Através da legitimação do discurso científico, comprometido com seu modelo fragmentário de conhecimento, os interesses econômicos se sobrepõem ao dever social de proteção ao ambiente e aos animais (FAGUNDEZ, 2000, p. 102).

Diante desse quadro, e do limite crítico a que está sendo sujeitada a vida, é imprescindível compreender o papel do Direito e da ética na construção de um novo paradigma jurídico, centrado na proteção da vida em suas diversas formas. Romper a lógica vigente do biocídio, como definido por Sônia T. Felipe (FELIPE, 2014, p. 302), é o ponto que unifica todos os saberes em prol da preservação da vida e superação de um modus vivendi marcado pelo sofrimento. 


\title{
3 LEI AROUCA: LEGISLAÇÃO VIGENTE NO BRASIL SOBRE EXPERIMENTAÇÃO ANIMAL
}

A norma específica que regula atualmente os procedimentos para o uso científico de animais no Brasil é a Lei 11.794, de 08 de outubro de 2008. Conhecida como Lei Arouca, esta revogou a Lei 6.638, de 08 de maio de 1979, bem como regulamentou o inciso VII do $§ 1$ do art. 225 da Constituição Federal.

\begin{abstract}
Art. 225. Todos têm direito ao meio ambiente ecologicamente equilibrado, bem de uso comum do povo e essencial à sadia qualidade de vida, impondo-se ao Poder Público e à coletividade o dever de defendê-lo e preservá-lo para as presentes e futuras gerações.

$\S 1^{\circ}$ Para assegurar a efetividade desse direito, incumbe ao Poder Público:[...]

VII - proteger a fauna e a flora, vedadas, na forma da lei, as práticas que coloquem em risco sua função ecológica, provoquem a extinção de espécies ou submetam os animais a crueldade. [...] (grifo nosso)
\end{abstract}

A norma regulamentar tem como propósito definir e limitar as hipóteses em que a experimentação animal pode ser instrumento de ensino e pesquisa científica. Trata-se de estabelecer parâmetros conciliatórios entre a necessidade do desenvolvimento da ciência e de proteção aos animais.

$\mathrm{Na}$ área do ensino, a Lei Arouca dispõe que apenas as instituições de ensino superior ou estabelecimentos de educação profissional técnica de nível médio da área biomédica podem utilizar animais para atividades educacionais. O esforço em limitar as instituições de pesquisa autorizadas a promover experimentação animal representa um esforço em ampliar a proteção aos animais, sem, contudo, vedar o uso dos seres vivos como objeto de ciência.

Já em relação à pesquisa científica, esta Lei traz uma ampla lista de conceitos, permitindo o uso dos animais em experimentos de pesquisas relacionadas com ciência básica, ciência aplicada, desenvolvimento tecnológico, produção e controle da qualidade de drogas, medicamentos, alimentos, imunobiológicos e instrumentos. Pela extensão das áreas em que são permitidos experimentos animais, pode-se afirmar que a norma é bastante permissiva em relação a tal prática. Tal afirmação é reforçada pela tendenciosa e comprometida composição dos órgãos criados para gerir a experimentação animal.

Ademais, a Lei Arouca, no intuito de regulamentar a experimentação animal, criou o Conselho Nacional de Controle de Experimentação Animal - CONCEA. Este órgão tem a função de formular normas para a utilização humanitária de animais, bem como estabelecer técnicas e procedimentos em consonância com as convenções internacionais das quais o 
Brasil seja signatário. O CONCEA é também competente para monitorar técnicas alternativas que substituam o uso do animal em experimentos.

Quanto à composição, o CONCEA é presidido pelo Ministro da Ciência e Tecnologia. Também integra o CONCEA um representante de cada um dos seguintes órgãos: Conselho Nacional de Desenvolvimento Científico e Tecnológico - CNPq, Ministérios da Educação, Meio Ambiente, Saúde, Agricultura Pecuária e Abastecimento, Ciência e Tecnologia, Conselho de Reitores das Universidades do Brasil - CRUB, Academia Brasileira de Ciências, Sociedade Brasileira para o Progresso da Ciência, Federação das Sociedades de Biologia Experimental, Colégio Brasileiro de Experimentação Animal, Federação Nacional da Indústria Farmacêutica. Aliando-se a essas autoridades, devem também integrar o CONCEA "02 (dois) representantes das sociedades protetoras de animais legalmente estabelecidas no País".

Para obter credenciamento junto ao CONCEA, é indispensável que a instituição pleiteante efetue a constituição prévia de Comissões de Ética no Uso de Animais - CEUAs. Cada CEUA deve ser integrada por médicos veterinários, biólogos, docentes, pesquisadores e um representante de sociedades protetoras dos animais.

Constata-se que, tanto na composição do CONCEA quanto dos CEUAs, os representantes de sociedades protetoras dos animais são minoria. Por sua minoria numérica, tais membros têm diminuto poder de persuasão nesses órgãos, compostos majoritariamente por cientistas, médicos, pesquisadores, acadêmicos e até representantes da poderosa indústria farmacêutica. Desta forma, por maior que sejam os interesses declarados na proteção dos animais, a composição dos órgãos fiscalizadores compromete sua atuação com os interesses imediatos da lucrativa indústria da experimentação animal. Nesse sentido, alertou Sonia T. Felipe que:

Há interesses econômicos gigantescos por detrás das pesquisas com fármacos. Para ter uma ideia do peso desses interesses, basta considerar o exemplo estadunidense, onde $50 \%$ dos impostos investidos em pesquisa médicas destinam-se a experimentos em modelo animal. (FELIPE, 2014, p.114)

Com a promulgação da Lei Arouca o legislador outorgou às CEUAs competências costumeiramente atribuídas ao poder público. Dentre tais competências, merecem destaque a de cumprir e fazer cumprir as normas, determinar a compatibilidade de procedimentos com a legislação, manter cadastro dos procedimentos e pesquisadores, expedir certificados, notificar 
autoridades sanitárias, bem como determinar a paralização das atividades da experimentação em animais.

Além disso, a representatividade social é nula nos órgãos tomadores de decisão técnica. Tal fator acarreta demasiada permissividade e obscuridade quanto aos critérios que autorizam a experimentação em animais. Um exemplo dessa situação é o silêncio sobre a legitimidade dos fins pelos quais se autoriza o uso dos animais em pesquisa. Comumente, os órgãos de controle permitem a experimentação animal para fins socialmente questionáveis, como para a produção de cosméticos, perfumaria e higiene pessoal. A predominância da decisão técnica nos órgãos de controle finalmente isenta a sociedade de seu dever de defesa e preservação dos animais constitucionalmente prevista.

Assim, percebe-se que a Lei Arouca é ineficaz ao regulamentar o inciso VII do § 1o do art. 225 da Constituição Federal, principalmente no que tange à vedação de práticas cruéis aos animais. Esta não se constituiu instrumento normativo suficiente para fazer cumprir a Declaração Universal dos Direitos dos Animais, especificamente no que concerne à proibição de sofrimento físico dos animais em experimentação.

\section{PROJETOS DE LEI ALTERADORES DA LEI AROUCA}

Pelas polêmicas questões acima levantadas, grupos sociais diversos levantaram a necessidade de alterações na Lei Arouca. Por isso, tramitam, atualmente, três Projetos de Lei que visam alterá-la, todos na Comissão de Ciência e Tecnologia, Inovação, Comunicação e Informática (CCT).

As alterações têm o escopo de vedar a utilização de animais em pesquisas para produção de produtos cosméticos e de higiene pessoal. Entre os projetos está o Projeto de Lei da Câmara (PLC) nº 70, de 2014 (Projeto de Lei no 6.602, de 2013, na origem), de autoria do Deputado Ricardo Izar. Tal projeto tramita em conjunto com Projetos de Lei do Senado (PLS) $n^{\circ} 438$, de 2013, do Senador Valdir Raupp, e n 45, de 2014, do Senador Álvaro Dias. Todas essas proposições deverão ser posteriormente enviadas à Comissão de Meio Ambiente, Defesa do Consumidor e Fiscalização e Controle (CMA).

O Senador Cristóvão Buarque é o relator desses projetos junto à Comissão designada para analisá-los. O relator resumiu a finalidade de cada projeto, em relatório publicado no dia 23/09/15: 
O art. $1^{\circ}$ do PLC $n^{\circ} 70$, de 2014, altera o art. 14 da Lei ${ }^{\circ} 11.794$, de 8 de outubro de 2008, para vedar a utilização de animais de qualquer espécie em atividades de ensino, pesquisa e testes laboratoriais que visem à produção e ao desenvolvimento de produtos cosméticos e de higiene pessoal e perfumes quando os ingredientes tenham efeitos conhecidos e sabidamente seguros, enquanto no caso dos ingredientes terem efeitos desconhecidos, a vedação será até cinco anos, contado do reconhecimento de técnica alternativa capaz de comprovar a segurança para o uso humano. As alterações do art. $1^{\circ}$ também proíbem o uso de bloqueadores neuromusculares ou de relaxantes musculares em substituição a substâncias sedativas, analgésicas ou anestésicas e a reutilização do mesmo animal depois de alcançado o objetivo principal do projeto de pesquisa. Além disso, o art. 1o determina que: as técnicas alternativas internacionalmente reconhecidas serão aceitas pelas autoridades brasileiras em caráter prioritário; em programa de ensino, sempre que forem empregados procedimentos traumáticos, vários procedimentos poderão ser realizados num mesmo animal, desde que todos sejam executados durante a vigência de um único anestésico e que o animal seja sacrificado antes de recobrar a consciência; para a realização de trabalhos de criação e experimentação de animais em sistemas fechados, serão consideradas as condições e as normas de segurança recomendadas pelos organismos internacionais aos quais o Brasil se vincula.

Os arts. $2^{\circ}$ e $3^{\circ}$ do PLC $n^{\circ} 70$, de 2014, modificam a Lei $n^{\circ} 11.794$, de 2008, para aumentar o valor das multas referentes às penalidades administrativas no caso de instituições e pessoas físicas, respectivamente.

[...]

Já o PLS n ${ }^{\circ} 438$, de 2013, altera em seu art. 10 o $\$ 3^{\circ}$ do art. $1^{\circ}$ da Lei 11.794 , de 8 de outubro de 2008, para proibir o uso de animais em testes de produtos cosméticos. $\mathrm{O}$ $\underline{\operatorname{art.~} 2^{\circ}}$ da proposição determina que a lei resultante do projeto entre em vigor na data de sua publicação.

Por sua vez, o art. $1^{\circ}$ do PLS n ${ }^{\circ} 45$, de 2014, acrescenta à Lei no 11.794 , de 2008, o art. 14-A que veda a utilização de animais na pesquisa e no desenvolvimento de produtos cosméticos e de higiene pessoal, enquanto o art. $2^{\circ}$ estabelece o prazo de vigência da lei resultante do projeto. (grifo nosso) (BUARQUE, 2015, http://www25.senado.leg.br/web/atividade/materias/-/materia/118217)

\section{Os Projetos $n^{\circ} 438 / 13 n^{\circ}$ e 45/14 provenientes do Senado possuem textos normativos} mais incisivos quanto à vedação da utilização de animais em pesquisa de cosméticos. $\mathrm{O}$ Projeto $n^{\circ} 438 / 13$ avançou um pouco mais sobre a matéria, posto que também incluiu a vedação do uso de animais em pesquisas de produtos de higiene pessoal. Ambos projetos previam a proibição já da data de sua publicação caso aprovados. Nesse sentido segue a justificativa do PLS nº 438/13, da lavra do Senador Valdir Raupp:

O banimento dos testes cosméticos em animais já é existente em diversos países. A União Européia (EU) proíbe a realização desse tipo de teste, inclusive em relação aos cosméticos importados fora da EU.

A partir de junho do corrente ano a Índia não aceita mais testes em cobaias animais para fins cosméticos. No mesmo sentido, Israel e Canadá também proibiram a realização desses testes.

[...] 
O site da Revista Exame publicou, no último dia 7 de outubro, matéria em que a organização Humane Society International (HSI) protocolou petição, acompanhada de relatório técnico, no Conselho Nacional de Controle de Experimentação Animal (CONCEA), vinculado ao Ministério da Ciência, Tecnologia e Inovação, alegando que esse tipo de teste é dispensável nos dias de hoje, não se justificando a sua prática. Conforme a organização a realização de testes em animais é antiética e podem ser substituídas por outras técnicas. (grifo nosso) (RAUPP, 2013, p.2 http://www.senado.leg.br/atividade/rotinas/materia/getPDF.asp?t=138920\&tp=1)

O mesmo argumento foi apresentado pelo Senador Álvaro Dias, na justificativa do PLS n ${ }^{\circ} 45 / 2014$ :

\begin{abstract}
Essa é também uma tendência mundial, já que a utilização de animais para o desenvolvimento desses produtos foi proibida na União Europeia. Já existem diversas alternativas para avaliações de segurança nessas pesquisas, a exemplo da modelagem biológica, da modelagem computadorizada e de métodos "in vitro" baseados no cultivo de células, sem a necessidade de submeter animais a $\begin{array}{lll}\text { procedimentos cruéis. } & \text { (DIAS, 2014, }\end{array}$ http://www.senado.leg.br/atividade/rotinas/materia/getPDF.asp?t=145590\&tp=1)
\end{abstract}

Ambos projetos estavam mais alinhados ao que prevê a Constituição Federal e a Declaração dos Direitos Animais, pois reconheciam que existem técnicas substitutivas às pesquisas que causam sofrimento aos animais. As justificativas constatam que o banimento destas pesquisas é uma tendência mundial.

Porém, desde abril de 2015, os Projetos do Senado perderam o caráter terminativo e passaram a tramitar em conjunto com o Projeto de Lei da Câmara $n^{\circ} 70$. É, este último projeto, muito menos assertivo em relação à proteção dos animais e, portanto, muito mais alinhado aos interesses da indústria da experimentação do que os projetos provenientes do Senado.

A justificativa apresentada no PLC $\mathrm{n}^{\circ} 70$ menciona que, em pesquisa realizada pelo IBOPE, dois terços dos brasileiros são contrários à utilização de animais em testes laboratoriais para a produção de cosméticos. O mesmo documento também relata que a empresa Natura, líder no mercado brasileiro de cosméticos, é a única empresa que eliminou tal prática. Outro argumento econômico sólido trazido na justificativa do PLC $\mathrm{n}^{\circ} 70$ é a tendência mundial em banir produtos cosméticos testados em animais, o que acabaria por impedir a exportação de produtos brasileiros para os países que já adotaram essas medidas (IZAR, 2013, p.07).

Retomando o argumento anterior, tal projeto é muito menos incisivo na tutela aos animais se comparado aos PLs provenientes do Senado. Enquanto estes proibiam a prática de experimentação animal nas pesquisas destinadas à produção de cosméticos e produtos do gênero, o novo PL n. 70 prevê tal proibição apenas quando os ingredientes utilizados forem 
reconhecidamente seguros ao uso humano ou quando se tratar de produtos cosméticos acabados. Em caso de ingredientes com efeitos desconhecidos, poderá ser efetuada a experimentação animal pelo prazo de cinco anos, contados do reconhecimento de técnica alternativa capaz de comprovar a segurança para uso humano. Deste modo, apenas partes dos experimentos seriam banidos, sendo permitida a continuação de pesquisas em animais quando os ingredientes testados tenham efeitos desconhecidos.

Nesse ponto, depara-se com a remissão do Direito perante a ciência. O legislador, pelo texto do PL, renuncia ao poder decisório outorgado pela sociedade e submete a decisão de interesse público à ciência. Tal postura tem, por consequência, a liberalização de experimentos em animais.

O desenvolvimento de técnicas alternativas ao uso de animais em experimentação deve ser promovido por pesquisadores e pela própria indústria farmacológica. Evidente que, se tal técnica acarretar maiores custos financeiros, não haverá incentivo para que indústria os procure. Este já é um problema mundialmente reconhecido não apenas na experimentação animal como em outros setores da ciência.

\begin{abstract}
Como poderemos comprovar com detalhes mais adiante, uma das fórmulas de decisão do sistema jurídico na incerteza científica e técnica consiste em enviar um componente importante da decisão ao próprio sistema da técnica. Uma fórmula recente, mas muito difundida na legislação e amplamente ensaiada, sobre questões ambientais. Assim, as licenças para a instalações com impacto ambiental são concedidas com a condição de que a instalação vá incorporando a melhor tecnologia disponível para reduzir ou neutralizar os efeitos poluentes da sua atividade. $\underline{\mathrm{A}}$ autoridade competente para conceder a licença não decide sobre a componente técnica, com uma complexidade e incerteza que excede seu conhecimento, e faz remissão ao sistema da técnica para determinar o que é considerado em cada setor a melhor tecnologia disponível para evitar ou reduzir a poluição.

Pois bem, pôde-se comprovar de forma muito clara, especialmente nos países pioneiros na aplicação da dessa fórmula de licença para instalações industriais Canadá, Estados Unidos, mas também Europa - que departamentos de pesquisa e inovação tecnológica das indústrias envolvidas fecham ou bloqueiam linhas de pesquisa que muito provavelmente conduziriam ao desenvolvimento de tecnologias altamente eficazes na redução de poluição - por exemplo, um novo material para a construção de painéis de isolamento de ruído - e que, por isso mesmo, ao ser então a melhor tecnologia disponível, resultaria exigível sua incorporação às instalações industriais do setor. A questão é que essa tecnologia poderia ter um custo elevado ou se não tivesse ela mesma, sim o teria no processo de sua incorporação à instalação, ao requerer reformas importantes - e portanto ser contrária aos interesses e cálculos econômicos da indústria, que decide, então, fechar ou abandonar as correspondentes investigações e programas de inovação tecnológica. (grifo nosso) (PARDO, 2015, p.102)
\end{abstract}

Não há nenhuma garantia do desenvolvimento de técnicas alternativas à experimentação animal, principalmente se tais técnicas aumentarem os custos da indústria farmacológica. Por razões econômicas elementares, a indústria será omissa no financiamento 
pesquisas que possam lhe trazer prejuízos. Assim, a tendência é a continuação do uso de animais em experimentos, por serem mais baratos e descartáveis.

Ademais, o prazo de cinco anos para os laboratórios se absterem de efetuar testes em animais após o conhecimento de técnicas alternativas atende unicamente ao mercado da experimentação animal. Não há nenhuma outra justificativa para tal situação ocorrer quando é cientificamente comprovada a eficiência de técnicas de pesquisa que não impliquem em sofrimento de qualquer espécie. As justificativas de todos os projetos de lei apresentados nesse estudo reconhecem a existência de técnicas alternativas a experimentação animal em pesquisas de produtos cosméticos. É, portanto, desnecessário o acréscimo da exceção temporal que ainda permite os testes de produtos cosméticos em animais.

Em sua análise, o relator dos projetos de lei na Comissão de Ciência e Tecnologia senador Cristóvão Buarque - declarou a prejudicialidade das iniciativas mais benéficas aos animais oriundas do Senado. Justificou sua posição por reconhecer as iniciativas do Senado como mais recentes que o PLC 70/2014, visto que o projeto originário deste último seria o $\mathrm{n}^{\circ}$ 6.602, de 2013. Sob tal argumento cronológico, o relator aprovou o PLC 70/2014 com emendas, em detrimento de projetos de maior tutela aos animais.

Apesar desse fato, as emendas foram muito bem recebidas pela comunidade defensora dos direitos dos animais, especialmente pela supressão do prazo de 05 (cinco) anos para adaptação às técnicas alternativas. As emendas garantem que em 03 (três) anos após sua sanção, ficará proibido qualquer teste em animais para produtos cosméticos, independentemente da existência de técnicas alternativas. Se o laboratório não conseguir demonstrar a segurança do produto sem o experimento em animais, não poderá lançá-lo no mercado.

Entre as outras alterações do Projeto, foi incluída a proibição de venda de ingredientes e produtos de higiene pessoal, cosméticos e perfumes testados em animais após 03 (três) anos da publicação da lei. Também foi definido claramente o que são cosméticos, produtos de higiene pessoal e perfumes, com a alteração do $\S 8^{\circ}$, do art. 14 da Lei Arouca:

$\S 8^{\circ}$ Para as finalidades desta Lei entende-se por produtos de higiene pessoal, cosméticos e perfumes: preparações constituídas por substâncias naturais ou sintéticas, de uso externo nas diversas partes do corpo humano, pele, sistema capilar, unhas, lábios, órgãos genitais externos, dentes e membranas mucosas da cavidade oral, com o objetivo exclusivo ou principal de limpá-los, perfumá-los, alterar sua aparência e ou corrigir odores corporais e ou protegê-los ou mantê-los em bom estado. 
Porém, o entusiasmo das ONGs animalistas foi breve. O PLC 70/2014, que deveria ser votado com as emendas pela Comissão de Ciência e Tecnologia (CCT) no dia 29 setembro de 2015 , foi retirado de pauta e aparece em sua tramitação oficial no portal do Senado como matéria com a relatoria.

\section{ESTATUTO DOS ANIMAIS COMO LIMITADOR DA EXPERIMENTAÇÃO ANIMAL - A RESOLUÇÃO DA POLÊMICA PARA ALÉM DO PLC 70/2014}

No dia 23 de setembro de 2015 foi proposto, junto ao Senado Federal, o Projeto de Lei do Estatuto dos Animais, que tramita sob o $\mathrm{n}^{\circ} \mathrm{PLS} / 631 / 2015$. De autoria do Senador Marcelo Crivella, este Estatuto tem seus objetivos previstos no artigo $1^{\circ}$, que assim dispõe:

\footnotetext{
Art. $1^{\circ} \mathrm{O}$ objetivo da presente Lei é assegurar e proteger a vida e o bem-estar dos animais em todo o território nacional.

$\S 1^{\circ}$ Ninguém deverá, por razões não justificáveis, causar dor, sofrimento ou lesão moral aos animais.

$\S 2^{\circ} \mathrm{O}$ disposto nesta Lei aplica-se aos animais das espécies classificadas como filo

Chordata, subfilo Vertebrata, observada a legislação ambiental.
}

Segundo o PLS, o Estatuto é destinado à proteção dos animais classificados como filo Chordata, subfilo Vertebrata “(...) que englobam animais que têm, como características exclusivas, um encéfalo grande dentro de uma caixa craniana e uma coluna vertebral. São cerca de 50 mil espécies, desde peixes primitivos até aves e mamíferos" (RODRIGUES, Edilson, 2016)

O PLS relembra no item "Justificação" que o artigo 225 da Constituição Federal impõe ao Poder Público o dever de proteger a fauna e a flora. Menciona o mesmo item que entre as proteções previstas na Carta constitucional está a vedação expressa de práticas que provoquem a extinção de espécies ou submetam os animais a crueldade.

\footnotetext{
Encontra-se reconhecido, portanto, em nosso te to normativo constitucional, o valor intrínseco auferido aos animais, eis que atos cruéis não serão tolerados, de modo que todo o desenvolvimento científico, tecnológico, econ mico e social devem se pautar por esta premissa, indispens vel a um desenvolvimento nacional sustent vel. (PLS/631/2015, 2015, p.11)
}

No mesmo documento, o autor do PLS alerta que, apesar da previsão constitucional, não existe legislação específica que regulamente de forma clara e objetiva um estatuto de proteção à vida e do bem-estar animal, que vede, especialmente, práticas que se apresentem cruéis e danosas. Ademais, destaca o mesmo Senador que países como Alemanha, Áustria e Estados Unidos há muito tempo já possuem legislações que vedam a dor e o sofrimento 
animal. A própria sociedade tem cobrado atitudes contra estas pr ticas, "a e emplo das discuss es envolvendo o uso de animais em pesquisas científicas ou o mero utilitarismo e prazer dos humanos em a es que causam sofrimento e dano desnecess rios aos animais" (PLS/631/2015, 2015, p.12).

Com a aprovação do PLS conforme o seu texto original, ninguém estaria autorizado a causar dor e sofrimento aos animais sem razões justificáveis. $\mathrm{O}$ art. $1^{\circ}$. acima transcrito do PLS proíbe não somente infligir dor física, como também veda o comprometimento do bemestar animal em ampla acepção. Essa inovação no tratamento da matéria pode ser reconhecida como autêntica proteção ao patrimônio moral dos animais. Porém, tal inovação foi logo extirpada do Projeto de Lei original por meio da emenda proposta pelo Senador Antonio Anastasia, relator do PLS na Comissão de Constituição e Justiça do Senado Federal (CCJ) em 16 de março de 2016, que alterou substancialmente o texto original:

\footnotetext{
Art. $1^{\circ}$ Esta Lei institui o Estatuto dos Animais e disciplina san es contra o seu descumprimento.

Par grafo nico. O disposto nesta Lei aplica-se aos animais das espécies classificadas no filo hordata, subfilo ertebrata, e ceto a espécie humana.

(...)

Art. $3^{\circ}$ inguém dever causar dor ou sofrimento aos animais.

$\S 1^{\circ}$ Excetuam-se do disposto no caput, os casos de controle de zoonoses, controle de espécies invasoras e de ensino e pesquisa cientifica na área da saúde, expressamente previstos na legislação, quando não houver método que evite totalmente a dor e o sofrimento, devendo ser adotadas todas as me medidas disponíveis para reduzi-los ao máximo.

$\S 2^{\circ} \mathrm{O}$ abate de animais, para fins comerciais, ser ob eto de legisla ão específica, com a ado ão de métodos que minimizem, o $\mathrm{m}$ imo possível, o sofrimento e a dor dos animais. (grifo nosso)
}

A supressão da garantia contra lesão ao patrimônio moral dos animais do texto do art. $1^{\mathrm{o}}$ foi justificada pelo Senador Antonio Anastasia. Em seu parecer, explica que a legislação não trata os animais como sujeitos de direitos, tal como os seres humanos ou pessoas jurídicas; portanto, os animais não seriam destinatários da mesma proteção jurídica conferidas àqueles.

Além da exclusão da tutela do patrimônio moral dos animais, outra emenda apresentada pelo relator excluiu a e pressão "por raz es não ustific veis" no dispositivo que proíbe atos que causem danos e sofrimento aos animais. Tal emenda teve como razão problemas de "insegurança jurídica". Em substituição, o Senador acrescentou hipóteses de exceções previstas nos parágrafos $1^{\circ}$ e $2^{\circ}$ já mencionados. (ANASTASIA, 2016 p. 3)

Finalmente, em 30 de março de 2016 o Estatuto dos Animais foi aprovado pela 
Comissão de Constituição e Justiça na forma do substitutivo do relator Antonio Anastasia, contendo, além dessas mencionadas emendas, outras que extrapolam o escopo do presente artigo.

Em análise dos trechos substitutivo ora descritos, verificou-se nas emendas um aparente retrocesso em relação ao texto original no tocante à tutela dos animais. A previsão legal de exceções que justificam medidas que causem sofrimento aos animais relativiza a tutela total inicialmente prevista. Casos como os de controle de zoonoses e de espécies invasoras, de ensino e pesquisa científica na rea da sa de, além do abate de animais para fins comerciais constituem as hipóteses taxativas de exceção à tutela desses seres.

Porém, ao contrário do que pareceria ser um retrocesso em uma primeira observação, o texto demonstra um considerável avanço no que tange à experimentação animal. Isso porque, mesmo com as exceções legalmente previstas, subsistiriam limites ao uso de animais para a pesquisa científica. O texto do PLS/631/2015, após emendas na CCJ, excepciona das vedações ao sofrimento dos animais a utilização destes em experimentos típicos de pesquisas na área da saúde. Assim, mesmo que de forma tácita, o texto veda o sofrimento dos animais em pesquisas alheias aos propósitos da área de saúde, incluindo no rol de vedações aquelas relacionadas à fabricação de produtos de higiene pessoal e cosméticos e de outros fins considerados menos nobres (FELIPE, 2015, p. 67).

O PLS vai além ao estender a vedação da utilização de animais em experimentos, mesmo que na área da saúde, quando dos animais. A norma em tramitação prevê que devem ser adotadas todas as medidas disponíveis para reduzir a dor e o sofrimento dos animais ao $\mathrm{m}$ imo. Pode-se concluir que se houver métodos de pesquisa conhecidos que possam substituir o uso de animais em experimentos, estes obrigatoriamente devem ser adotados, mesmo que a prática comum ainda seja a experimentação animal.

Caso o Estatuto dos Animais seja aprovado conforme o texto atual, o argumento econômico não poderá mais ser arguido para justificar o uso de animais em experimentos caso haja outro tipo de método a ser aplicado. Se o esse mesmo Estatuto permanecer tal como foi aprovado na CCJ, o que poderia ser interpretado como um retrocesso ou ao menos uma concessão ao complexo industrial/econômico, é na verdade um grande avanço para os grupos que defendem o fim da prática da experimentação animal, não somente no que tange a produtos cosméticos e de higiene pessoal, mas também na área da saúde. 


\section{CONCLUSÃO}

A autorização do uso de animais para experimentação de fármacos e cosméticos é de legitimidade bastante discutida. Isso porque outros métodos de pesquisa são reconhecidos como eficientes e substitutivos pelos próprios cientistas. Além disso, muitos atores sociais, como organizações não-governamentais, têm trazido informações e situado o debate na mídia nacional, ainda que de maneira fragmentária e pontual.

A vedação dos experimentos de pesquisa que tenham como necessário o sofrimento e a dor de animais, especialmente para produção de cosméticos, passou a constituir a pauta de reivindicações de movimentos sociais junto ao Congresso Nacional. O fundamento básico dessa demanda é a possibilidade de substituição dos testes e mesmo dos produtos. Assim, a justificativa para os testes em animais simplesmente desaparece do campo da necessidade humana: resta apenas o fator econômico da indústria da dor.

Perceber a necessidade de limites à experimentação animal requer, por sua vez, renegar um modelo de ciência completamente indiferente ao sentido ético; exige reconhecer a relação intrínseca entre conhecimento científico e respeito à vida. Essa dimensão, entretanto, está obscurecida pelo paradigma da cegueira, responsável pela segregação e individualização da vida. O resgate da ideia de poli-super-meta-máquina permite a percepção da vida como um fenômeno complexo e não fragmentário.

Essa base ética impõe uma visão problematizante do uso dos animais em pesquisas e, portanto, das normas atuais que autorizam tais práticas. Tendo como pressuposto a proteção da vida e sua não-instrumentalização, é consequência o questionamento dos limites do uso de seres vivos para a produção industrial, especialmente de cosméticos.

Como resultado desse enfrentamento, movimentos sociais de defesa dos direitos animais informam a sociedade sobre a necessária superação desse padrão científico da dor legítima, encontrando respaldo social. Daí todo o sentido da demanda pela produção legislativa condizente com a tutela máxima da vida, constitucionalmente prevista no artigo 225 . 
Sob tal expectativa, a Lei Arouca (n. 11.794/2008), norma atualmente regulamentadora do uso de animais em experimentos científicos no Brasil, é insuficiente. Por essa norma, a finalidade das pesquisas científicas baseadas em experimentos sobre animais não é questionada. A autorização de tais experimentos depende da apreciação de Conselhos técnicos (CEUAs) internos às próprias empresas do ramo, e, em última instância, ao cadastramento destas no CONCEA. Ambos órgãos, pela Lei Arouca, detém uma composição eminentemente técnica, sob a qual são escamoteados interesses econômicos na continuidade de atividades de experimentação animal. O controle e a participação social nos processos decisórios sobre pesquisas que envolvem o uso de seres vivos são, sob o atual regramento jurídico, praticamente irrelevante.

Tem-se que a norma foi formulada muito mais visando a autorização do que a limitação do uso de animais em pesquisas científicas. Além disso, a norma é indiferente à finalidade da pesquisa, considerando como válido todo propósito de produção, sem estabelecer limites inaceitáveis ao sofrimento e à dor.

Essa insuficiência da Lei Arouca motiva a demanda por um novo regramento jurídico do setor. Inicialmente, é preciso colocar em evidência a finalidade da pesquisa, vedando, desde pronto, o sofrimento animal por motivos fúteis. Ademais, as práticas laboratoriais precisam estar comprometidas em evitarem o sofrimento a todo o custo, representando inclusive o resguardo de vidas desnecessariamente descartadas pela repetição inócua de procedimentos de teste. Por outro lado, a substituição de procedimentos de experimentação de produtos em animais deve ser imediata, quando tecnicamente comprovada tal possibilidade.

Em atenção a tais demandas, inclusive cientificamente corroboradas, dois projetos de Lei começaram a tramitar no Senado Federal: PLS nº 438, de 2013, do Senador Valdir Raupp, e $\mathrm{n}^{\mathrm{o}} 45$, de 2014, do Senador Álvaro Dias. Incorporando tais demandas, esses projetos sucumbiram ao interesse da indústria da pesquisa, com sua substituição pelo projeto de Lei da Câmara dos Deputados, o PLC no 70, de 2014 (Projeto de Lei nº 6.602, de 2013, na origem). Ameno, em geral, com relação às vedações do uso de animais em experimentos, o PLC foi ainda alvo dos lobbies das indústrias destinadas a tal finalidade, sendo retirado de pauta de discussão da Câmara dos Deputados.

Paralelamente à retirada de pauta dos projetos que visam alterar a Lei Arouca, foi proposto no Senado o PLS 631/2015 que prevê a instituição do Estatuto dos Animais. Com um texto mais abrangente e avançado, o Estatuto foi aprovado na CCJ em março de 2016. 
Segundo o substitutivo aprovado, apenas serão permitidos experimentos com animais em pesquisas relacionadas à saúde, vedando, por exclusão, a utilização de animais nas demais áreas, inclusive em pesquisas de ingredientes para produtos de higiene pessoal e cosméticos. Em exercício interpretativo do texto do PLS 631/2015, também se pode concluir que, caso existam tecnologias que substituam os experimentos em animais, estas obrigatoriamente deverão ser adotadas, inclusive na área da saúde.

O projeto de lei que institui o Estatuto dos Animais deve tramitar em outras comissões no Senado para, após, ser encaminhado para a Câmara dos Deputados. Portanto, ainda pode sofrer modificações ou ficar em tramitação por longo período. Porém, mostra-se, até o momento, como uma melhor alternativa em relação aos projetos que visam especificamente alterar a Lei Arouca.

Percebe-se, portanto, que a questão do uso de animais em experimentos científicos está distante de ser pacificada no Brasil. Enquanto isso, as indústrias vinculadas continuam a impor, como se normal e única via fosse, o padrão da dor na produção de cosméticos e fármacos, além de outros produtos de consumo humano.

O respeito e a proteção da vida como padrões orientadores da produção jurídicanormativa representa a reconciliação do Direito com sua dimensão ética. A adoção desses limites pela sociedade, composta de diversos interesses, por sua vez, reúne ética e pesquisa. A unidade entre ética, ciência e Direito é representada, no campo normativo, pelo Biodireito. Somente quando considerados os limites de respeito à vida na produção científica e jurídica é que se pode cogitar a efetivação das expectativas éticas pelas instituições. Nesse sentido, a aposta no Biodireito, mais que uma questão de legitimidade institucional, representa a condição suficiente e necessária para o enfrentamento de modelos normativos em crise, fundamentados unicamente nos interesses do mercado.

\section{REFERÊNCIAS BIBLIOGRÁFICAS}

BRASIL. Senado Federal. Projeto de Lei da Câmara $\mathbf{n}^{\mathbf{0}}$ 70/2014. Altera o dispositivos dos arts. 14, 17 e 18 da Lei 11.794/08, para dispor sobre a vedação da utilização de animais em atividades de ensino, pesquisas e testes laboratoriais com substâncias para o desenvolvimento de produtos de uso cosméticos em humanos e aumentar os valores da multa no caso de violação dos dispositivos. Disponível em: $\square$ http://www.senado.leg.br/atividade/rotinas/materia/getPDF.asp?t=153287\&tp=1 $\square$. Acesso em: 05 out. 2015. 
BRASIL. Senado Federal. Projeto de Lei do Senado $n^{0}$ 438/2013. Altera o art. $1^{\mathbf{o}}$ da Lei $\mathrm{n}^{\circ} 11.794$, de 8 de outubro de 2008, para proibir o uso dos animais em testes de produtos cosméticos.

Disponível

em:

http://www.senado.leg.br/atividade/rotinas/materia/getPDF.asp?t=138920\&tp=1. Acesso em: 05 out. 2015

BRASIL. Senado Federal. Projeto de Lei do Senado no 45, de 2014 Altera a Lei no 11. , de de outubro de 200 , para proibir a utiliza ão de animais na pesquisa e no desenvolvimento de produtos cosméticos e de higiene pessoal. Disponível em http://www.senado.leg.br/atividade/rotinas/materia/getPDF.asp?t=145590\&tp=1. Acesso em 05 de out. 2015.

BRASIL. Senado Federal. Projeto de Lei do Senado $\mathbf{n}^{\mathbf{0}}$ 631, de 2015 Institui o Estatuto dos Animais e altera a redação do art. 32 da Lei no 9.605, de 12 de fevereiro de 1998. Disponível em http://www25.senado.leg.br/web/atividade/materias/-/materia/123276. Acesso em 04 de abr. 2016.

BRASIL. Senado Federal. Parecer da Comissão de Ciência, Tecnologia, Inovação, comunicação e Informática, sobre o Projeto de Lei da Câmara no 70, de 2014 (Projeto de Lei $\mathrm{n}^{\circ}$ 6.602, de 2013, na origem), do Deputado Ricardo Izar, que altera dispositivos dos arts. 14, 17 e 18 da Lei $n^{\circ} 11.794$, de 8 de outubro de 2008, para dispor sobre a vedação da utilização de animais em atividades de ensino pesquisa e teste laboratoriais com substâncias para o desenvolvimento de produtos de uso cosméticos em humanos e aumentar os valores de multa nos caso de violação de seus dispositivos, e os Projetos de Lei do Senado n 438 de 2013, do Senador Valdir Raupp, que altera o art. $1^{\circ}$ da Lei no 11.794 , de 8 de outubro de 2008, para proibir o uso de animais em testes de produtos cosméticos, e $\mathrm{n}^{\circ} 45$, de 2014 , do Senador Álvaro Dias, que altera a Lei $\mathrm{n}^{\circ} 11.794$, de 8 de outubro de 2008, para proibir a utilização de animais na pesquisa e no desenvolvimento de produtos cosméticos e higiene pessoal. Disponível em: http://www25.senado.leg.br/web/atividade/materias/-/materia/118217. Acesso em: 05 nov. 2015.

BRASIL. Senado Federal. Parecer da Comissão de Constituição e Justiça, sobre o Projeto de Lei do Senado $\mathbf{n}^{\mathbf{0}}$ 631, de 2015, do Senador Marcelo Crivella, que institui o Estatuto dos Animais e altera a redação do art. 32 da Lei $n^{\circ}$ 9.605, de 12 de fevereiro de 1998. Disponível em: 〈http://legis.senado.leg.br/mateweb/arquivos/mate-pdf/190361.pdf> Acesso em: 04 abr. 2016.

FAGÚNDEZ, Paulo Roney Ávila. Direito e holismo: introdução a uma visão jurídica de integridade. São Paulo: LTr, 2000.

. O direito e a hipercomplexidade. São Paulo: LTr, 2003.

FELIPE, Sônia Terezinha. Ética e experimentação animal: fundamentos abolicionistas. 2.ed. Florianópolis: Editora da UFSC, 2014.

MORIN, Edgar. Introdução ao pensamento complexo. 3.ed. Tradução de Dulce Matos. Lisboa: Instituto Piaget, 2001. 
O método I: a natureza da natureza. 2.ed. Tradução de Ilana Heineberg. Porto Alegre: Sulina, 2005.

PARDO, José Esteve. O desconcerto do Leviatã: política e direito perante as incertezas da ciência. Tradução de Flávia França Dinnebier e Giorgia Sena Martins. São Paulo: Inst. O Direito por um Planeta Verde, 2015.

RODRIGUES, Edilson, Estatuto dos Animais é aprovado pela CCJ. 2016 Disponível em https://www12.senado.gov.br/noticias/materias/2016/03/30/estatuto-dos-animais-e-aprovadopela-ccj/. Acesso em 02/04/2016.

SANTOS, Boaventura de Sousa. A Crítica da razão indolente contra o desperdício da experiência. . ed. São Paulo ortez, 2009. 